\title{
Relationship between Academic Optimism and Classroom Management Styles of Teachers_Case Study: Elementary School Teachers in Isfahan
}

\author{
L. Moghtadaie ${ }^{1} \&$ R. Hoveida ${ }^{1}$ \\ ${ }^{1}$ Department of Educational Sciences and psychology, University of Isfahan, Isfahan, Iran \\ Correspondence: L. Moghtadaie, Department of Educational Sciences and psychology, University of Isfahan, \\ Isfahan, Iran. Tel: 91-3226-6739. E-mail: baran_7141@yahoo.com
}

Received: April 3, 2015 Accepted: June 5, 2015 Online Published: October 28, 2015

doi:10.5539/ies.v8n11p184

URL: http://dx.doi.org/10.5539/ies.v8n11p184

\begin{abstract}
The purpose of this study was to investigate the relationship between classroom management styles of the teachers and their academic optimism. In this study, three types of classroom management styles (interventionist style, interactionist style, and non-interventionist style) have been considered. Research community is all public primary school teachers in the Isfahan province in academic year 2014-2015. The sample size was calculated using the formula of Cochran 384. It is a multi-stage cluster sampling method. Classroom management style has been calculated using standard questionnaires of classroom management style of Wolfgang and Glickman (1986). The academic optimism variable was evaluated using academic optimism questionnaire of A. Hoy, Tarter, and W. Hoy (2006) in a sample of 384 teachers. The results showed that there is a significant relation between classroom management style of the teachers and their academic optimism and the correlation coefficient equal to $39 \%$ was obtained and the correlation coefficient of $47 \%$ was obtained between the academic optimism and non-interventionist classroom management, and the correlation coefficient of $43 \%$ was obtained between the academic optimism and interactionist classroom management, and the correlation coefficient of $24 \%$ was obtained between the academic optimism and interventionist classroom management that is significant.
\end{abstract}

According to the results, the classroom management style is a variable that has relation with academic optimism and at academic opportunities it must be emphasized.

Keywords: interventionist style, interactionist style, non-interventionist style, academic optimism

\section{Introduction}

Development of any society depends on the quality of education in the community. Education is as a widespread and pervasive system and is also a fundamental element of modern society. Classroom is as a social sub-system of the educational system having unique features and distinguishes it from other institutions and social organizations.

Learning and teaching will not be effective unless it is in a class that is well managed. The teacher plays multiple roles in the classroom that certainly one of the most important of which is classroom management. At an inappropriately-managed classroom, students and teachers will be damaged and students learn less than what is intended. Conversely, a well-managed classroom provides an environment that in which teaching and student learning will flourish the students. Classroom management is the first level of educational management and higher levels of management is the school administration, it is considered the zone management and the management of whole of educational system, and has fundamental impact on formation of education structure and teaching process and building the character and process of mental, emotional, education of the students (Sabbaghian, 2001). Amirnezhad (2010) believes that classroom management is one of the factors that teachers, administrators, and policy makers in education consider it as a main and important issue, that has been considered from past as a complex issue to improve the academic quality. Establishing and managing of the classroom is considered as the most time-consuming activities of the teachers. When most of the class time is spent on discipline problems, in practice less time for teaching and learning lessons would remain. Safavi (1948) considers the classroom management as leading the classroom through curriculum, organization of work and resources, organizing the environment to enhance the monitoring of student progress and predicting potential 
problems. In another definition, classroom management is the art of applying the special knowledge and use of classroom management skills in directing students towards the goals of the society. (www.sajadandishe.ir, 2014, p. 2). The classroom management includes the activities of the teacher to motivate the students and involve them, cause discipline and their participation in the learning process. Classroom management are every day skills in other words, each teacher learns the classroom management by effort and accuracy, but everyday experience. Academic progress of the students is of relation with the classroom management by teachers. Based on this, Martin, Shoho, and Yin (2003) believed that the first responsibility of the teacher is to manage the class so that he can provide the best environment for learning, and so that the students can achieve the academic progress. The purpose of the classroom management is to provide an environment so that the students are willing to learn and they do not feel they are forced to do so. Optimal management of class can have a major impact on student learning. In fact, the good management of the classroom has positive advantages for the students and at a larger scale for the education and society. However, Oliva (2000) wrote that the findings of Galop Institution show that the classroom management has been always one of the main important problems during 1970-1990. The classroom management is so important that some believe that one cannot study education (learning) and classroom management separately because both of them have impact in providing good conditions of the class (Samadi et al., 2008). Wolfgang and Glickman (1980) considered the class management as the efforts of the teacher to manage the activities of class including social interaction, students' behavior and learning and based on this they considered four aspects of education, communication, structure and psychological environment, at the class management. According to Wolfgang (2004), teachers form their behavior pattern at classroom management based on their beliefs about children's development and learning, that each behavior style pattern can have different aspects on the growth of the students. He relied on the psychology of learning and classroom management, and based on this has outlined a conceptual framework of the three classroom management approaches on the continuum of control, which are: interventionist approach, interactionist approach and non-interventionist approach. At this spectrum, as much as we advance from interventionist approach to non-interventionist approach, the control rate is reduced and cooperation and responsibility of the students are increased.

- Interventionist approach: This approach emphasizes on this that the teacher should make a decision until there is no problem in the classroom. Since the beginning of the school year, classroom teacher is obliged to impose rules and regulations and students are also required to enforce those laws. Reinforcement process via rewards of the desirable behaviors and get back the scores if the inappropriate behaviors occurred, is effective at this method. The teacher's authority in this way is quite reserved and the teacher uses this authority at setting and maintaining rules.

- Interactionist approach: At this method, the class problems are considered the natural consequence of the students' presence and it is not unexpected and like the problem-solving activities at the class will be solved.

- Non-interventionist approach: This method is based on an average of the two methods and teacher involvement in solving problems is very small. The main purpose of this method, is promoting the personal development of students and their freedom. At this method, the teacher has counseling relation with the students and at class activities has supportive role of the students. This method has the least authority for the teacher and instead, more emphasis is to strengthen the relationship between teacher and student (Yazdi \& Aali, 2008). It seems that more specific in-depth researches are to maximize the utility of the classroom as the current needs of education that many variables affect this area. The study attempted to examine the relationship between academic optimism and classroom management style and by this was we want to find practical solutions for desirable management of the classroom according to the academic optimism.

The concept of academic optimism has been created from inside the researches about the positive psychology, social capital and comprehensive equipment of the schools. First Hoy et al. introduced this term, Theoretical basis of academic optimism including Bandura's self-efficacy theory, the theory of social capital of Coleman, Culture and organizational climate studies of Hoy et al., and the learned optimism of Seligman (Asgari \& Fotovat, 2014). Academic optimism is a personal belief of teachers that the teacher can cause the success of the students by creating an active and positive learning environment (Mazare'ei, 2010). First Hoy et al. (2006) that studied positive psychology introduced the academic optimism. The positive psychology considers the purpose of academic optimism discovering and describing the desirable and optimal educational environments. A class that is based on optimism should emphasize on opportunities and facilities, happiness, altruism and trust, and an optimist teacher should focus on the positive aspects and the quality of the students of a classroom, school and community (Asgari \& Fotovat, 2014, p. 115). Some believe that Seligman (1996) with a theory about Learned Helplessness, has enters academic optimism factor into the psychological area. He considers academic optimism 
a kind of cycle to explain the events and believes that it is consisted of three components of continuity, learning and personalizing. Continuity means that pessimists consider the negative events continuous and the optimists consider the positive events continuous. Learning means that the optimists consider the failures continuous and the optimists consider the success pervasive. Personalizing in the view of the optimists it means caused by the external causes, and in the view of the pessimists mean caused by internal factors (Noori \& Janbozorgi, 2008). According to Seligman and Sigsntmahaly, optimism is considered a personal trend and it includes the willingness of the person to this that he has experienced good achievements and should avoid bad results; they believe that optimism factor has an important role in academic success of the students so that they can share the success of the students to the limit of talent and motivation because optimism causes optimism and academic optimism of the teacher would result in optimism of students and finally would lead to the success of the students, however Coleman et al. (1966) believe that Social economical status is a factor that affects the student performance and is so powerful that one cannot overcome it. It means that according to them, success is substantially based on the student background or economic and social factors but according to Hoy et al. (2007) in addition to economic and social factors, there are other factors at school that affect their function and according to them academic optimism as a strong element affects the learning of the students. Hoy, Tarter and Hoy (2006) describes the academic optimism as a strong force that leads the function of students. The structure of academic optimism of a teacher includes three indices of Trust in students, parents, Academic emphasis on creation a positive and challenging environment for the students and Self efficacy of the teacher (Bierd et al., 2010).

The diagram of academic optimism is derived from the Bandura's (1997) social recognition theory that represents aspects of cognitive, emotional and behavioral, and describes the causal relationships between them (Hoy \& Diplaz, 2007) that these variables have interrelationships with each other and depend on each other so that would increase the success of the students for example when the self-efficiency of a teacher is increased it causes a high level of educational trust and vice versa.

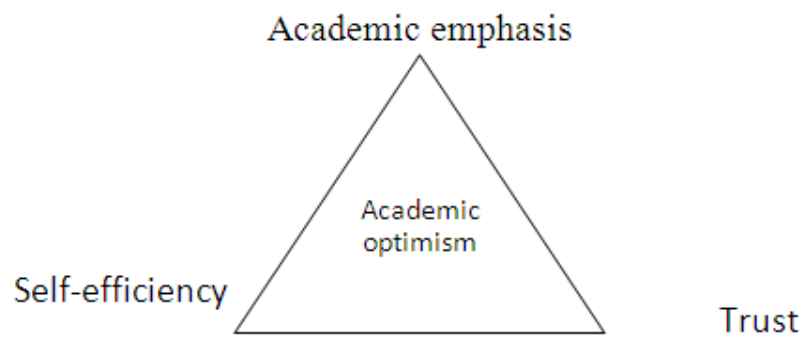

Figure 1. The causal interrelations in academic optimism in the schools (Hoy et al., 2006)

The academic emphasis has relation with the aspects of behavior, teacher's collective efficacy, cognitive and academic trust of the parents and students with emotional aspect (W. Hoy, Tarter, \& A. Hoy, 2006). Academic emphasis is the norm and behavior description of the school environment at the level of class as well as school level (MacGuigan \& Hoy, 2006). The academic emphasis depends on this that how much the school has considered the progress and academic success part of its goals; at these conditions the goals are very good but are achievable for the students, learning environment is regular and serious, the students are with high motivation to try hard and academic achievement are important to them. Academic emphasis is a central behavior that would lead into encouraging to academic success of the students (W. Hoy, Tarter, \& A. Hoy, 2006). Academic progress of the students is located at the main core of academic emphasis so that it emphasizes on the success and progress of all the students even the students having problem with the traditional classroom structure. The teachers create a student-centered educational environment in where risk taking is promoted (Hoy et al., 2008). Teachers with a human approach deal with the discipline in the classroom and effectively promote the optimism and flexibility and self-determination of the students. The classroom that is based on the student-centered factor has emphasis on the interests, abilities, knowledge and needs of the students. It would create more positive relationships so that students are willing to help each other. So the academic emphasis is based on the behaviors that would lead into the success of the students, valuing the hard work and learning. Collective self-efficiency of teachers has root at the self-efficiency theory of Bendura. Teachers believe that they have the skills needed to help students to achieve their educational goals and create change in learning of 
students specially the ones that have no enough motivation or have challenging behaviors (Teshman \& Moran, 2008). If teachers believe that they can create change and students can learn, they can raise their expectations, have more effort and persist against their problems (Hoy et al., 2008). Palmay (2012) in a study examined the relationship between academic optimism, at schools and academic achievement of students. The study findings showed that the component of academic emphasis of the academic optimism components at reading and mathematics has significant impact on academic progress of students.

Hoy et al. (2006) in a study called academic optimism of schools, a force for progress of the students concluded that academic optimism has significant results on academic success of students.

Arya-pooran, Azizi, and Dinarvand (2013) in a study examined the relation of class management style of teachers with motivation and progress of math of the elementary school students; and the results showed that there is a significant relation between the interactionist style of teachers with math motivation and between interactionist style and interventionist style of teachers with math progress of the students. The interactionist class management style is the strongest variable to predict math motivation of students.

Yazdi and Aali (2008) in a study examined the effect of classroom management styles and growth of the metacognitive skills of students. The results showed that the students of the interactionist teachers in comparison with the students of the interventionist teachers have higher metacognitive skills, and there is a positive and significant relation between the metacognition of the students and the score of academic progress of them.

Asgari and Fotovat (2013) in a study examined the relation between scientific optimism of teachers and Organizational Citizenship Behavior; the results showed that there is a positive and significant relation between scientific optimism, citizen behavior, optimistic trends and the student-oriented activities of teachers.

Based on the theoretical foundations and the research background, the following theoretical model is proposed:

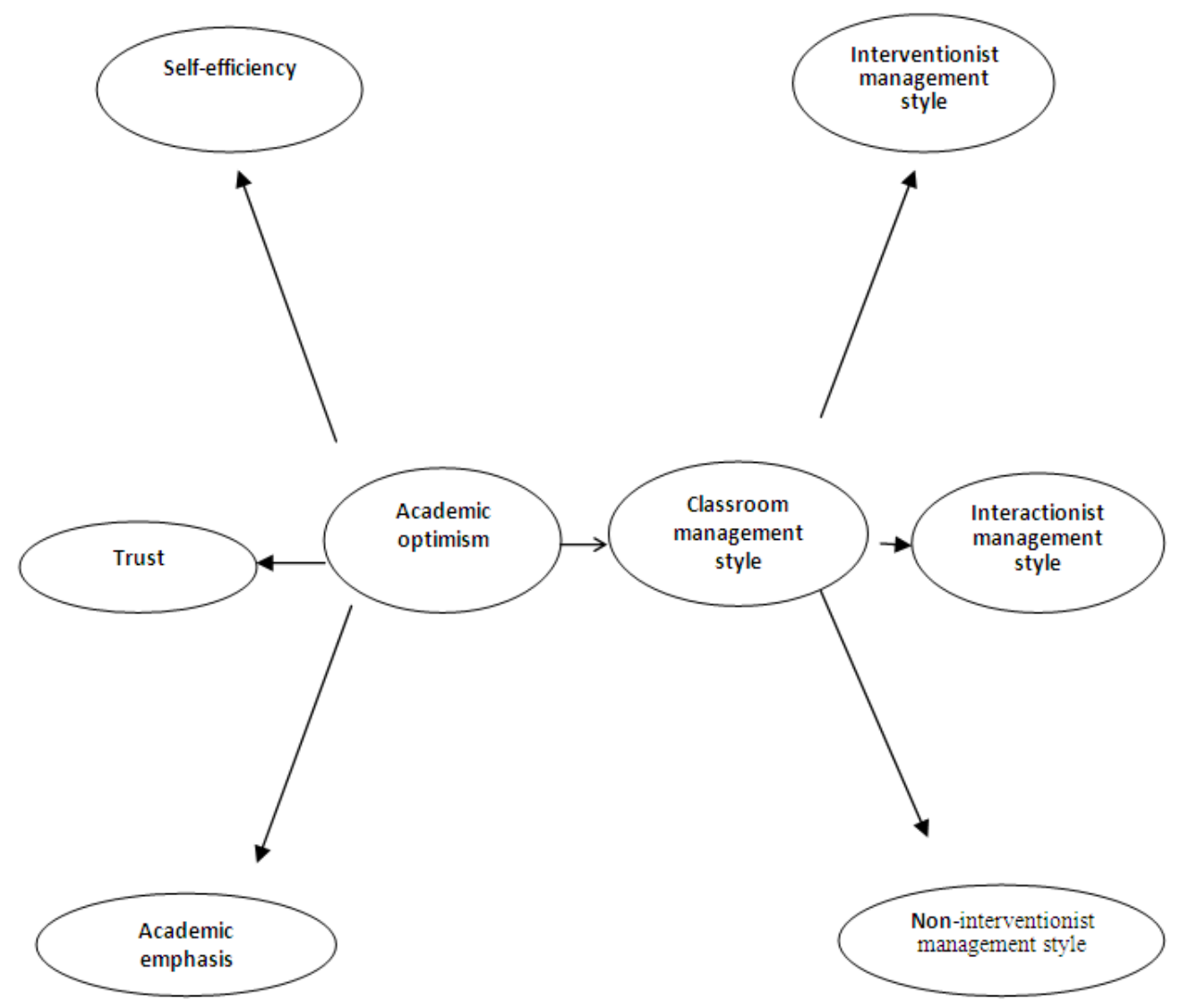

Figure 2. Research conceptual model

The available researches show that the appropriate classroom management would improve the learning of students and would lead to academic progress of them. The background study shows that there has not yet been a 
study that had examined the relation between the class management styles and academic optimism, and up to now only the relation of each of variables with other variables have been examined.

The present research in order to meet the available gap in this area, has studied the relation between the three styles of classroom management and academic optimism of teachers. According to what was said, the purpose of this study is to answer this basic question. Have the classroom management styles of academic optimism a relation with teachers of them?

\section{Method}

The method is based on documents and survey. in the documentary stage, the theoretical foundations of academic optimism and classroom management style were studied using the books, specialized journals and websites and by this the levels and dimensions and background of these two variables were studied, and academic optimism was determined by the indices of academic emphasis, self-efficiency and trust and classroom management style with the dimensions of dimensions of the styles of interventionist, interactionist and interventionist.

The class management style was evaluated using the questionnaire of class management style of Wolfgang and Glickman (1986). Grading of the questionnaire is an interval scale (Never $=1$, somewhat $=2$, usually $=3$, and always=4). The resulting scores are in the range of 25 to 100 .According to the pattern of Wolfgang, a high score in this range represents the interventionist management style and low score is non-interventionist style. The interactionist style is placed at a middle point of this range between the two styles; so that the scores $25-40$ are related to non-interventionist, and 41-75 to interactionist style and 76-100 to interventionist style. The reliability is obtained $7 \%$ by Cronbach's alpha coefficient (Aali \& Yazdi, 2005). The validity of the questionnaire was confirmed by experts in the field. The academic optimism factor was used by the academic optimism questionnaire, Hoy et al. (2006). The reliability of questionnaire has been obtained $67 \%$ by Cronbach's alpha coefficient and the validity of the questionnaire was confirmed by experts in the field. The statistical population was all of the male and female teachers working in academic year of 2014-2015 in public elementary schools of Isfahan city. The sample size has been estimated by use of the Cochran formula and for confidence level of $95 \%$ and the maximum dispersion of 384 people. It has been a multi-stage cluster sampling method. The questionnaires were collected verbally.

\subsection{The Reliability of the Questionnaire}

Table 1. Calculation of reliability coefficients for the secondary aspects of academic optimism and style of classroom management

\begin{tabular}{|c|c|c|c|}
\hline Coefficient value & Reliability coefficient & Dimensions (indices) & Variable \\
\hline 0.7 & Cronbach's Alpha & Non-interventionist style & \multirow{6}{*}{ 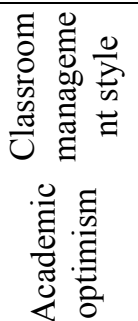 } \\
\hline 0.6 & Cronbach's Alpha & interactionist style & \\
\hline 0.8 & Cronbach's Alpha & Interventionist style & \\
\hline 0.7 & Cronbach's Alpha & Self-efficiency & \\
\hline 0.6 & Cronbach's Alpha & Trust & \\
\hline 0.7 & Cronbach's Alpha & Academic emphasis & \\
\hline
\end{tabular}

As you see the secondary aspects of questionnaire have a good reliability (coefficient of reliability of all the factors are higher than 6.0)

\section{Findings}

Descriptive research findings are in Tables 2, 3, 4 and 5. 
Table 2. Frequency distribution of respondents according to age groups

\begin{tabular}{ccc}
\hline Percentage & Frequency & Age groups \\
\hline 5.2 & 20 & Under 22 \\
49.47 & 190 & $30-39$ \\
34.89 & 134 & $40-49$ \\
10.41 & 40 & 50 and above \\
\hline
\end{tabular}

Table 3. Frequency distribution of respondents according to gender

\begin{tabular}{ccc}
\hline Percentage & Frequency & Age groups \\
\hline $58 \%$ & 194 & Female \\
$42 \%$ & 190 & Male \\
$100 \%$ & 384 & Total \\
\hline
\end{tabular}

Of the respondents, $58 \%$ were female and $42 \%$ male.

Table 4. Frequency distribution of respondents according to types of classroom management style

\begin{tabular}{lll}
\hline Percentage & Frequency & Types of classroom management style \\
\hline 7.5 & 29 & Non Interventionist \\
0.50 & 192 & interaction-oriented \\
42.4 & 163 & interventionist \\
100 & 384 & Total \\
\hline
\end{tabular}

As you see, most of respondents had interventionist style and then interaction classroom management style and non-interventionist style

Table 5. Frequency distribution of respondents according to the level of optimism

\begin{tabular}{lll}
\hline Percentage & Frequency & level of academic optimism \\
\hline 26.04 & 100 & Low \\
36.4 & 140 & Average \\
37.5 & 144 & High \\
100 & 384 & Total \\
\hline
\end{tabular}

As you see, most of teachers have high optimism.

\subsection{Analytical Results}

The variables of academic optimism, non-interventionist style, interactionist style and interventionist style were measured at interval level and to test of hypotheses Pearson's correlation coefficient was used.

The special hypotheses:

- There is a relation between academic optimism of teachers and non-interventionist style.

- There is a relation between academic optimism of teachers and interactionist style.

- There is a relation between academic optimism of teachers and interventionist style.

At null hypothesis, it is assumed that there is no correlation between independent variable and dependent variables, and at the opposite hypothesis it is assumed that there is a correlation between independent variable and dependent variables. 
A) Testing the special hypotheses

Table 6. Test of Pearson's correlation coefficient for special hypotheses

\begin{tabular}{lll}
\hline Academic optimism & Independent variable & Dependent variable \\
\hline $47 \%$ & Pearson's correlation coefficient & \\
$22 \%$ & Effect coefficient & Non-Interventionist style \\
$00 \%$ & Significance level & \\
$43 \%$ & Pearson's correlation coefficient & \\
$18 \%$ & Effect coefficient & Interactionist style \\
$00 \%$ & Significance level & \\
$24 \%$ & Pearson's correlation coefficient & \\
$0.05 \%$ & Effect coefficient & Interventionist style \\
$00 \%$ & Significance level & \\
\hline
\end{tabular}

The Table results indicate that between academic optimism and non-interventionist style of the studied case the correlation coefficient equal to 0.74 was obtained and the significance level is less than 0.05 ; this coefficient is significant and we can generalize the results of the sample population with $95 \%$ of statistical population, so hypothesis null is rejected and the research hypothesis is accepted, and with respect to the obtained effect coefficient we can expect that up to $22 \%$ of variance of non-interventionist style is related to academic optimism of teachers.

Also, the results of test of the second special hypothesis shows that the correlation factor between academic optimism and interactionist style is $43 \%$ in the statistical sample and since the significance level is less than 0.05 , we can generalize the obtained result with $95 \%$ of confidence to the statistical population so the hypothesis null is rejected and the study hypothesis is accepted. In addition, with respect the effect factor we can expect that up to 0.18 of variance of interactionist style is determined by academic optimism.

The special third hypothesis suggests that correlation is $24 \%$ between interventionist style and academic optimism of the sample and since the significance level is less than $0.05 \%$, this value is a significant factor and so we can generalize the sample population with $95 \%$ to the statistical population, so the hypothesis null is rejected and the study hypothesis is accepted, also with respect to 0.05 impact factor, we can expect that up to $0.05 \%$ percent of variance of interventionist style is determined by academic optimism.

In general with respect to the results we can see that academic optimism with interventionist style has a higher correlation than interactionist style, and there is a lower correlation between academic optimism and interventionist style than the two other styles.

B) Testing the general hypothesis

Hypothesis: There is a relation between academic optimism and classroom management style.

Hypothesis null indicates that there is no relation between academic optimism and classroom management style and the opposite hypothesis indicates such a relation.

Table 7. Test of Pearson's correlation coefficient for the general hypothesis

\begin{tabular}{lll}
\hline Academic optimism & Independent variable & Dependent variable \\
\hline 0.39 & Pearson's correlation coefficient & \\
0.15 & Effect coefficient & Classroom management style \\
0.00 & Significance coefficient & \\
384 & Sample size & \\
\hline
\end{tabular}


As you can see, Pearson's correlation coefficient between classroom management style and academic optimism in the studied sample, the correlation is equal to 0.39 and since the significance level is less than 0.05 , so the obtained coefficient has a significant difference with zero and this correlation is significant so we can generalize the results of the sample population to the statistical population with $95 \%$ of confidence, so the hypothesis null indicating there is no relation between academic optimism and classroom management style is rejected and the study hypothesis is accepted. Also with respect the impact factor of 0.15 we can expect that up to 0.15 of variance of class management style variable is determined by academic optimism.

\section{Discussion and Conclusion}

The results of this study confirmed the study hypotheses. Based on what has been determined at general hypothesis, there is a significant relation between academic optimism and classroom management style of teachers. Testing of correlation coefficient showed that classroom management style of teachers has a high impact on learning and academic progress of students (Table 7).

Efficient management, teachers and creating required conditions to facilitate learning are necessary for the today society and would facilitate the formation of teaching-learning process. Classroom management style affects academic optimism and has impact on academic emphasis, self-efficiency and trust on students and parents.

According to the hypothesis results, there is a relation between academic optimism of teachers and non-interventionist style. We can acknowledge there is a positive and significant relation between academic optimism of teachers and non-interventionist style. In the non-interventionist style, it is believed by humanists that the children have internal motivation to recognize the real world and they do not need external stimulation because the growth is under nature. Non-interventionist teacher does not tell the students what is right and what is wrong or what should be done to solve the problem because he believes that the students are able to learn and control their behavior. So the student have the opportunity to co-operate in selecting the study materials, determining study method and keeping the classroom order and evaluating themselves that this affects academic optimism (Table 6).

The findings show that there is a relation between academic optimism of teachers and interactionist style and this indicates that there is a significant relation between academic optimism of teachers and interactionist style. The reason of this is that at interactionist style the class issues and problems would be solved by negotiation with the students or in other words the control of students' behavior is a common issue by teachers and learners, and since the goal of interactionist is help to learning and controlling of their behavior the teacher allows the students to monitor their function and judge again about their function. Gessler theoretical principles emphasize the fact that in managing the class rules about appropriate and inappropriate behaviors should be created during class and participation sessions at an interaction process between teacher and student and evaluation should be performed at a bilateral negotiation process. So the teachers with having an optimistic interpretive style concerning responsibility can increase academic progress of students (Table 6).

The findings of the hypothesis of "there is a relation between classroom management style of teachers and interventionist style", indicates that there is a positive and significant relation between academic optimism of teachers and interventionist style. One of the concepts affecting optimism of teacher and student academic progress is interventionist style. This approach is based on this fact that controlling of student behavior is the first responsibility of teacher. According to a behaviorist teacher the reason of misbehavior of students is the effect of outside forces and based on this belief he tries to change and improve involvement and control of behavior of students. An interventionist teacher with determining difficult Disciplinary Rules and trying to severely control the students would reduce student cooperation in class decisions and student academic progress. The students have no power and responsibility in learning and believe that the teacher can control, monitoring and correct their behavior (Table 6).

These findings are consistent with the results of studies by Aryanpooran, Azizi, and Dinarvand (2013), Yazdi and Aali (2008).

In general, we can say that the significant relation of classroom management styles with academic optimism of teachers is justifiable. So the styles used by teachers can affect academic optimism of them and other members of school and can lead to desirable results.

\section{References}

Amirnezhad, A. (2010). Class management. Province weekly. Bushehr: Birami.

Ansari, H. (2009). Role of styles of classroom management in student academic motivation of high school of Horand zone (Thesis, Islamic Azad University-Tabriz). 
Aryapooran, S., Azizi, F., \& Dinarvand, H. (2013). Relation of classroom management style of teachers withmotivation and math progress of elementary school. School psychology, 2(1), 23-41.

Asgari, A., \& Fotovat, Z. ( 2014). Teacher scientific optimism and organizational citizen behavior. Researches of Health System, 1, 10.

Association of California School Administrators. (2012). Transformational Leadership: Creating Academic Optimism.

Bart, R. J. (2010). Academic optimism and organizational climate: an Elementary school Effectiveness test of two measures. Tuscalooa, Alabama.

Coleman, J. S., Campbell, E. Q., Hobson, C. J., McPartland, F., Mood, A. M., Weinfeld, F. D. et al. (1966). Equality of educational opportunity. Washington, DC: U.S. Government Printing Office.

Eesazadegan, A., \& Maie, M. F., \& Marooei, M. (2014). Relation between Hope, optimism and academic meaning with academic function of pre-university students. School Psychology Quarterly, 10.

Golkar, R., Agha-Hosseini, T., \& Zarin, A. (1389). Disciplinary Strategies and techniques in the classroom of perspectives, models and approaches. Isfahan: Kankash.

Hoy, W. K., \& DiPaola, M. (2007). Essential ideas for the reform of American schools. Greenwich, CT: Information Age.

Hoy, W. K., Tarter, C. J., \& Hoy, A. W. (2006). Academic optimism of schools: A force for student achievement. American Educational Research Journal, 43(3), 425-446. http://dx.doi.org/10.3102/00028312043003425

Hoy, W. K., Tarter, C. J., \& Kottkamp, R. B. (1991). Open schools/healthy schools: Measuring organizational climate. Beverly Hills, CA: Sage.

Macpherson, K., \& Cater, C. (2009). The Possible Benefits Over Current Discipline Polices). Journal of Cross. Disciplinary perspectives in Education, 2(1), 59-69.

Martin, N. K., Shoho, A., \& Yin, Z. (2003). Attitudes and Beliefs Regarding Boston. Allyn and Bacon

Mazarei, F. (2010). Relation of Individual characteristics, styles of Identity and identity commitment with academic optimism of female and male teachers $(\mathrm{PhD}$ thesis, Tehran University, Faculty of Psychology and Educational Sciences).

McGuigan, L., \& Hoy, W. K. (2006). Principal Leadership: Creating a Culture of Academic Optimism to Improve Achievement for All Students. Leadership and Policy in Schools, 5, 203-229. http://dx.doi.org/10.1080/15700760600805816

Noori, N., \& Jan-Bozorgi, M. (1387). The relationship between progress motivation and optimism. Psychology and Religion, 2.

Oliva, P. (2000). Monitoring and guidance of education at today schools. Isfahan, Islamic Azad University-Khorasgan.

Sabbaghian, Z. (2001). Effective classroom management. Shahid Beheshti publication,Tehran.

Safavi, A. (1993). General Teaching Methods and Techniques. Samt publications, Tehran.

Wolfgang, C. H. (2004). Solving discipline and classroom management problems. New York: John Wiley and sons INC.

Wolfgang, C. H., \& Glickman, C. D. (1980). Solving discipline problems. Strategies for Research in the Schools, 10(2), 29-34.

Yazdi, A., \& Aali, A. (2008). Investigating the effect of class management styles on growth of Metacognitive skills of students. Education and Psychology Studies, 9(1).

\section{Copyrights}

Copyright for this article is retained by the author(s), with first publication rights granted to the journal.

This is an open-access article distributed under the terms and conditions of the Creative Commons Attribution license (http://creativecommons.org/licenses/by/3.0/). 